\title{
Waist circumference percentiles among Turkish children under the age of 6 years
}

\author{
Nihal Hatipoglu • M. Mumtaz Mazicioglu • \\ Serpil Poyrazoglu • Arda Borlu • Duygu Horoz • \\ Selim Kurtoglu
}

Received: 23 June 2012 / Accepted: 30 August 2012 / Published online: 27 September 2012

(C) The Author(s) 2012. This article is published with open access at Springerlink.com

\begin{abstract}
Waist circumference, a proxy measure of abdominal obesity, is associated with cardio-metabolic risk factors in childhood and adolescence. Although there are numerous studies about waist circumference percentiles in children, only a few studies cover preschool children. The aim of this study was to develop age- and gender-specific waist circumference smoothed reference curves in Turkish preschool children to determine abdominal obesity prevalence and to compare them with reference curves obtained from different countries. The design of the study was cross-sectional. A total of 2,947 children (1,471 boys and 1,476 girls) aged 0 6 years were included in the study. The subjects were divided according to their gender. Waist circumference was
\end{abstract}

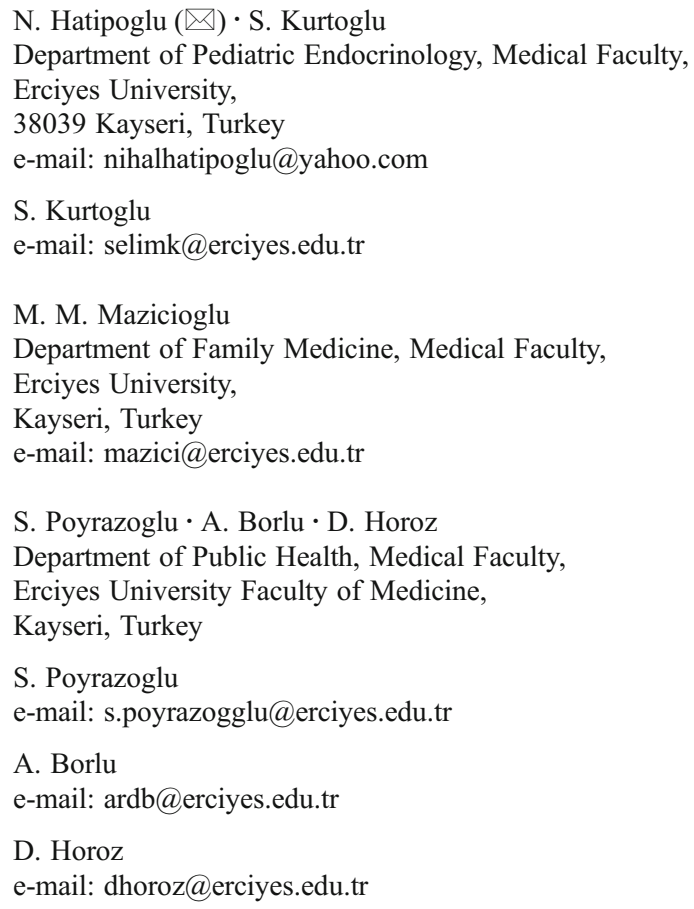

measured by using a standardized procedure. The age- and gender-specific waist circumference reference curves were constructed and smoothed with LMS method. The reference values of waist circumference, including 3rd, 10th 25th, 50th, 75th, 90th, and 97th percentiles, and standard deviations were given for preschool children. Waist circumference values increased with age, and there were differences between genders. The prevalence of abdominal obesity was calculated as $10.1 \%$ for boys and $10.7 \%$ for girls. Having compared our data with two other countries' data, we found that our waist circumference data were significantly lower. This is the first cross-sectional study for age- and genderspecific references of 0 - to 6 -year-old Turkish children. The gender- and age-specific waist circumference percentiles can be used to determine the risk of central obesity.

Keywords Waist circumference reference values . Preschool children

\section{Introduction}

The prevalence of childhood overweight and obesity gradually increases, even in preschool-age children [29]. Globally, more than 20 million children who are below the age of 5 are overweight [44]. The finding that overweight in preschool children is an indicator of five times more overweight in adolescence and four times more overweight in adulthood is compared with normal-weight counterparts [28]. Since chronic conditions such as diabetes, cardiovascular disorders, hypertension, stroke, asthma, and certain neoplastic disorders may occur in late adulthood, prevention and early interventions for overweight or obesity are a real concern [5]. 
Although the body mass index (BMI) is used as a marker of obesity, it may be a less sensitive indicator in early childhood [32]. A few studies on preschool children showed a weak correlation between BMI and metabolic risk factors $[19,36]$. Thus, it may be considered that BMI is an unreliable marker in this age group since central adiposity which is associated with metabolic risk factors is not adequately reflected by BMI. Therefore, early identification of children's central adiposity is important $[40,41]$.

The waist circumference (WC), one of the anthropometric techniques, is strongly correlated with metabolic risk factors and now becomes widely used [23]. In addition, WC is an essential diagnostic criterion for metabolic syndrome according to the National Cholesterol Education Program (NCEP) Adult Treatment Panel III (ATP III) and the International Diabetes Federation (IDF) [40, 41]. There are recent reports indicating that the onset of risk factors for metabolic syndrome under the age of 10 years can be considered. The NCEP and IDF criteria for metabolic syndrome may be modified to explain metabolic risks under the age of 10 years $[14,30$, 45]. Thus, WC cutoffs and reference values in preschool children can be useful for identifying children with metabolic risk and might be helpful for early intervention.

The preschool age is a difficult group for achievement and anthropometric measure while school-age children are easily accessible. Therefore, although many countries have their own reference values for WC [1, 17-21, 27, 35, 39], a few studies cover preschool-age children [11, 12, 21, 37].

The aim of this study was to establish reference values of waist circumference in Turkish preschool children. This study provided the prevalence of abdominal obesity in preschool children of both sexes. Furthermore, 50th and 90th percentiles of WC were compared with the ones in a few other countries [11,37].
Table 1 Descriptive statistics for waist circumference for boys and girls by age

\begin{tabular}{|c|c|c|c|c|}
\hline \multirow[t]{2}{*}{ Age } & \multicolumn{2}{|c|}{ Boys } & \multicolumn{2}{|c|}{ Girls } \\
\hline & $n$ & Median (min-max) & $n$ & Median (min-max) \\
\hline 0-28 days & 108 & $31.00(28.00-34.00)$ & 108 & $31.00(26.00-40.00)$ \\
\hline 28 days -3 months & 49 & $38.00(30.50-44.80)$ & 44 & $37.50(31.50-45.00)$ \\
\hline $3-<6 \mathrm{~m}$ & 70 & $41.00(33.00-48.00)$ & 63 & $40.00(34.50-49.50)$ \\
\hline $6-<9 \mathrm{~m}$ & 78 & $42.00(35.05-53.05)$ & 64 & $41.13(32.00-49.00)$ \\
\hline $9-<12 \mathrm{~m}$ & 71 & $44.00(35.10-52.00)$ & 75 & $42.50(34.60-51.25)$ \\
\hline $12-<15 \mathrm{~m}$ & 58 & $43.63(39.50-51.00)$ & 56 & $43.50(38.50-50.00)$ \\
\hline $15-<18 \mathrm{~m}$ & 57 & $44.00(40.30-50.50)$ & 61 & $44.00(39.00-50.00)$ \\
\hline $18-<21 \mathrm{~m}$ & 54 & $44.00(39.50-51.00)$ & 73 & $43.80(39.00-50.00)$ \\
\hline $21-<24 \mathrm{~m}$ & 57 & $45.00(39.50-51.00)$ & 66 & $45.00(38.10-50.00)$ \\
\hline $24-<27 \mathrm{~m}$ & 36 & $46.40(41.00-52.00)$ & 52 & $46.00(41.00-53.00)$ \\
\hline $27-<30 \mathrm{~m}$ & 56 & $48.00(41.50-54.00)$ & 48 & $47.00(41.00-52.00)$ \\
\hline $30-<33 \mathrm{~m}$ & 57 & $48.00(41.00-54.00)$ & 48 & $46.70(41.00-51.00)$ \\
\hline $33-<36 \mathrm{~m}$ & 56 & $48.00(41.00-54.00)$ & 44 & $49.00(43.00-53.30)$ \\
\hline $36-<39 \mathrm{~m}$ & 50 & $48.75(45.00-55.50)$ & 51 & $49.00(43.00-57.00)$ \\
\hline $39-<42 \mathrm{~m}$ & 37 & $50.00(45.00-56.75)$ & 53 & $48.50(43.00-57.00)$ \\
\hline $42-45 \mathrm{~m}$ & 41 & $50.00(45.00-55.20)$ & 40 & $48.00(42.50-58.00)$ \\
\hline $45-<48 \mathrm{~m}$ & 51 & $49.50(45.50-56.40)$ & 44 & $50.75(42.50-58.00)$ \\
\hline $48-<51 \mathrm{~m}$ & 38 & $50.90(45.00-57.00)$ & 44 & $50.00(45.00-58.00)$ \\
\hline $51-<54 \mathrm{~m}$ & 41 & $51.00(45.00-62.00)$ & 45 & $51.00(45.00-61.30)$ \\
\hline $54-<57 \mathrm{~m}$ & 46 & $51.70(46.00-60.60)$ & 60 & $52.00(45.00-59.00)$ \\
\hline $57-<60 \mathrm{~m}$ & 44 & $52.00(48.00-61.00)$ & 38 & $51.50(45.80-61.50)$ \\
\hline $60-<63 \mathrm{~m}$ & 54 & $52.75(46.00-62.00)$ & 22 & $50.65(45.00-61.40)$ \\
\hline $63-<66 \mathrm{~m}$ & 47 & $52.00(46.00-63.00)$ & 46 & $52.75(46.00-61.00)$ \\
\hline $66-<69 \mathrm{~m}$ & 46 & $52.00(47.00-68.00)$ & 57 & $52.00(45.0-62.00)$ \\
\hline $69-<72 \mathrm{~m}$ & 47 & $52.00(46.00-66.00)$ & 55 & $52.00(45.00-61.00)$ \\
\hline $72-<75 \mathrm{~m}$ & 42 & $54.00(48.00-64.00)$ & 41 & $51.60(47.00-64.60)$ \\
\hline $75-<78 \mathrm{~m}$ & 30 & $51.75(47.00-60.00)$ & 35 & $51.50(47.00-62.00)$ \\
\hline $78-<81 \mathrm{~m}$ & 30 & $53.50(47.00-66.00)$ & 24 & $53.00(48.00-66.00)$ \\
\hline $81-<84 \mathrm{~m}$ & 20 & $55.00(47.10-66.00)$ & 19 & $53.00(47.00-66.00)$ \\
\hline
\end{tabular}




\section{Materials and methods}

Subjects

We analyzed the data of Anthropometry of the Turkish Children aged 0-6 years (ATCA-06). The ATCA-06 study was conducted from September 2009 to May 2010 in one of the five great cities of Turkey with about 1,200,000 residents. The sampling design of the study was a two-stage probability sampling for preschool children living in Kayseri.

The primary sampling unit was the family health centers (Aile Sagligi Merkezi, ASM) located in the city center and suburbs. At the first stage, children were selected from 21 ASMs in Kayseri by stratifying according to the socioeconomic levels of their parents. Children aged 0-6 years old were randomly selected among the list of district midwives and they were invited to ASMs with their parents.
Those infants and children, whose parents did not accepted, were invited again to participate in the study by midwives.

A total of 2,947 children (1,471 boys and 1,476 girls) whose parents gave consent were included in the study. After data collection, we removed 230 (119 boys and 110 girls, $7.9 \%$ of sample size) subjects from the study because of reasons such as missing data in the interviewing forms, children with growth disorders, or using any kind of medication which could interfere with growth. Then, to obtain normally distributed data, the higher and lower limits (3rd-97th percentiles) for each gender and quarter age were removed $(n=115)$. Chronological age was calculated by subtracting the date of birth from the date of observation. Each quarter year elapsed from their birthday was noted. The WHO group recommended that early growth patterns should be documented in intervals shorter than 3 months $[10,13]$. So, we calculated by age and gender in 0-6-year-old children in quarter-year intervals except for the 0-28-day newborn period.
Table 2 Smoothed age-specific waist circumference percentile values for boys

\begin{tabular}{|c|c|c|c|c|c|c|c|c|c|}
\hline Age & $3 p$ & $5 \mathrm{p}$ & $10 \mathrm{p}$ & $25 p$ & $50 \mathrm{p}$ & $75 p$ & $90 \mathrm{p}$ & $95 p$ & $97 \mathrm{p}$ \\
\hline $0-28$ days & 26.6 & 27.3 & 28.2 & 29.7 & 31.2 & 32.5 & 33.6 & 34.3 & 34.7 \\
\hline 28 days -3 months & 32.2 & 32.8 & 33.8 & 35.4 & 37.2 & 39.0 & 40.5 & 41.4 & 42.0 \\
\hline $3-<6$ & 34.9 & 35.5 & 36.5 & 38.2 & 40.0 & 42.0 & 43.7 & 44.8 & 45.5 \\
\hline $6-<9$ & 36.5 & 37.1 & 38.1 & 39.8 & 41.7 & 43.7 & 45.5 & 46.7 & 47.4 \\
\hline $9-<12$ & 37.7 & 38.3 & 39.2 & 40.9 & 42.8 & 44.9 & 46.8 & 48.0 & 48.7 \\
\hline $12-<15$ & 38.6 & 39.2 & 40.2 & 41.8 & 43.7 & 45.8 & 47.7 & 48.9 & 49.7 \\
\hline $15-<18$ & 39.4 & 40.0 & 40.9 & 42.6 & 44.5 & 46.6 & 48.5 & 49.8 & 50.6 \\
\hline $18-<21$ & 40.1 & 40.7 & 41.6 & 43.3 & 45.2 & 47.3 & 49.3 & 50.5 & 51.4 \\
\hline $21-<24$ & 40.8 & 41.4 & 42.3 & 43.9 & 45.9 & 48.0 & 50.0 & 51.3 & 52.2 \\
\hline $24-<27$ & 41.4 & 42.0 & 42.9 & 44.6 & 46.5 & 48.6 & 50.7 & 52.0 & 52.9 \\
\hline $27-<30$ & 42.0 & 42.6 & 43.5 & 45.2 & 47.1 & 49.3 & 51.4 & 52.7 & 53.6 \\
\hline $30-<33$ & 42.6 & 43.2 & 44.1 & 45.7 & 47.7 & 49.9 & 52.0 & 53.4 & 54.4 \\
\hline $33-<36$ & 43.1 & 43.7 & 44.6 & 46.2 & 48.2 & 50.4 & 52.6 & 54.1 & 55.1 \\
\hline $36-<39$ & 43.6 & 44.2 & 45.1 & 46.7 & 48.7 & 51.0 & 53.2 & 54.7 & 55.7 \\
\hline $39-<42$ & 44.1 & 44.6 & 45.6 & 47.2 & 49.2 & 51.5 & 53.8 & 55.3 & 56.4 \\
\hline $42-45$ & 44.5 & 45.1 & 46.0 & 47.6 & 49.7 & 52.0 & 54.4 & 55.9 & 57.0 \\
\hline $45-<48$ & 44.9 & 45.5 & 46.4 & 48.0 & 50.1 & 52.5 & 54.9 & 56.5 & 57.6 \\
\hline $48-<51$ & 45.3 & 45.8 & 46.8 & 48.4 & 50.5 & 52.9 & 55.4 & 57.1 & 58.2 \\
\hline $51-<54$ & 45.6 & 46.2 & 47.1 & 48.8 & 50.9 & 53.3 & 55.9 & 57.6 & 58.8 \\
\hline $54-<57$ & 46.0 & 46.5 & 47.5 & 49.1 & 51.3 & 53.7 & 56.3 & 58.1 & 59.3 \\
\hline $57-<60$ & 46.3 & 46.9 & 47.8 & 49.5 & 51.6 & 54.1 & 56.8 & 58.6 & 59.9 \\
\hline $60-<63$ & 46.6 & 47.2 & 48.1 & 49.8 & 51.9 & 54.5 & 57.2 & 59.1 & 60.4 \\
\hline $63-<66$ & 46.9 & 47.4 & 48.4 & 50.1 & 52.3 & 54.8 & 57.6 & 59.5 & 60.9 \\
\hline $66-<69$ & 47.2 & 47.7 & 48.6 & 50.4 & 52.5 & 55.2 & 58.0 & 60.0 & 61.4 \\
\hline $69-<72$ & 47.4 & 48.0 & 48.9 & 50.6 & 52.8 & 55.5 & 58.4 & 60.4 & 61.9 \\
\hline $72-75$ & 47.7 & 48.2 & 49.2 & 50.9 & 53.1 & 55.8 & 58.7 & 60.8 & 62.3 \\
\hline $75-78$ & 47.9 & 48.5 & 49.4 & 51.1 & 53.4 & 56.1 & 59.1 & 61.2 & 62.8 \\
\hline $78-81$ & 48.1 & 48.7 & 49.6 & 51.4 & 53.6 & 56.4 & 59.4 & 61.6 & 63.2 \\
\hline $81-84$ & 48.4 & 48.9 & 49.9 & 51.6 & 53.9 & 56.6 & 59.7 & 62.0 & 63.7 \\
\hline
\end{tabular}


The study protocol was approved by the Ethics Committee of Erciyes University. Parents' written consent was obtained prior to the study and the procedures were in accordance with those outlined by the Declaration of Helsinki.

\section{Measurements}

All measurements were done by well-trained technicians. Waist circumference was measured with a non-stretchable tape at the midpoint of the lowest rib cage and the iliac crest, to the nearest $0.1 \mathrm{~cm}$, at the end of a gentle expiration [43]. The circumference was measured without clothing. Central obesity was defined as WC higher than the 90th percentile [24].

Statistical analysis

Construction of the centile curves was performed with the LMS Chart Maker Pro version 2.3 software program (The Institute of Child Health, London), which fits smooth centile curves to reference data [8]. This method summarizes percentiles at each age based on the power of agespecific Box-Cox power transformations that are used to normalize data. These three quantities depend on age. The final curves of percentiles are produced by three smooth curves representing $L$ (Lambda, skewness), $M(\mathrm{Mu}$, median), and $S$ (Sigma, coefficient of variation) (LMS) [7]. Descriptive statistics for each quarter year (e.g., 3-8 m, etc.) within sex were calculated by SPSS version 15.0 (Chicago, IL, USA).

\section{Results}

There were 1,471 (50\%) boy and 1,476 (50\%) girl infants. The median waist circumference values increased with age for both study groups.

The descriptive statistics for waist circumference for boys and girls by age are given in Table 1 . In Tables 2
Table 3 Smoothed age-specific waist circumference percentile values for girls

\begin{tabular}{|c|c|c|c|c|c|c|c|c|c|}
\hline Age & $3 p$ & $5 \mathrm{p}$ & $10 p$ & $25 p$ & $50 p$ & $75 p$ & $90 p$ & $95 p$ & $97 p$ \\
\hline 0-28 days & 27.0 & 27.6 & 28.4 & 29.8 & 31.4 & 33.2 & 34.9 & 36.0 & 36.7 \\
\hline 28 days -3 months & 32.0 & 32.6 & 33.5 & 35.0 & 36.8 & 38.7 & 40.6 & 41.7 & 42.5 \\
\hline $3-<6$ & 34.5 & 35.1 & 36.0 & 37.6 & 39.5 & 41.5 & 43.3 & 44.5 & 45.2 \\
\hline $6-<9$ & 36.1 & 36.7 & 37.6 & 39.3 & 41.1 & 43.1 & 45.0 & 46.1 & 46.9 \\
\hline $9-<12$ & 37.3 & 37.9 & 38.8 & 40.4 & 42.3 & 44.3 & 46.2 & 47.3 & 48.1 \\
\hline $12-<15$ & 38.2 & 38.8 & 39.7 & 41.4 & 43.3 & 45.3 & 47.2 & 48.3 & 49.1 \\
\hline $15-<18$ & 39.0 & 39.6 & 40.5 & 42.2 & 44.1 & 46.1 & 48.0 & 49.2 & 50.0 \\
\hline $18-<21$ & 39.7 & 40.3 & 41.2 & 42.9 & 44.8 & 46.9 & 48.8 & 50.0 & 50.8 \\
\hline $21-<24$ & 40.3 & 40.9 & 41.9 & 43.5 & 45.5 & 47.6 & 49.6 & 50.8 & 51.6 \\
\hline $24-<27$ & 40.9 & 41.5 & 42.5 & 44.2 & 46.1 & 48.3 & 50.3 & 51.5 & 52.4 \\
\hline $27-<30$ & 41.5 & 42.1 & 43.1 & 44.7 & 46.7 & 48.9 & 51.0 & 52.3 & 53.2 \\
\hline $30-<33$ & 42.0 & 42.6 & 43.6 & 45.3 & 47.3 & 49.5 & 51.6 & 53.0 & 53.9 \\
\hline $33-<36$ & 42.5 & 43.1 & 44.1 & 45.8 & 47.8 & 50.1 & 52.2 & 53.6 & 54.6 \\
\hline $36-<39$ & 42.9 & 43.5 & 44.5 & 46.2 & 48.3 & 50.6 & 52.8 & 54.3 & 55.2 \\
\hline $39-<42$ & 43.3 & 43.9 & 44.9 & 46.7 & 48.8 & 51.1 & 53.4 & 54.9 & 55.9 \\
\hline $42-45$ & 43.7 & 44.3 & 45.3 & 47.1 & 49.2 & 51.6 & 53.9 & 55.5 & 56.5 \\
\hline $45-<48$ & 44.1 & 44.7 & 45.7 & 47.4 & 49.6 & 52.0 & 54.4 & 56.0 & 57.1 \\
\hline $48-<51$ & 44.4 & 45.0 & 46.0 & 47.8 & 50.0 & 52.4 & 54.9 & 56.5 & 57.6 \\
\hline $51-<54$ & 44.7 & 45.3 & 46.3 & 48.1 & 50.3 & 52.8 & 55.4 & 57.0 & 58.2 \\
\hline $54-<57$ & 45.0 & 45.6 & 46.6 & 48.4 & 50.7 & 53.2 & 55.8 & 57.5 & 58.7 \\
\hline $57-<60$ & 45.3 & 45.9 & 46.9 & 48.7 & 51.0 & 53.6 & 56.2 & 58.0 & 59.2 \\
\hline $60-<63$ & 45.5 & 46.2 & 47.2 & 49.0 & 51.3 & 53.9 & 56.6 & 58.4 & 59.7 \\
\hline $63-<66$ & 45.8 & 46.4 & 47.4 & 49.3 & 51.6 & 54.2 & 57.0 & 58.8 & 60.1 \\
\hline $66-<69$ & 46.0 & 46.7 & 47.7 & 49.5 & 51.9 & 54.5 & 57.3 & 59.2 & 60.6 \\
\hline $69-<72$ & 46.3 & 46.9 & 47.9 & 49.8 & 52.1 & 54.8 & 57.7 & 59.6 & 61.0 \\
\hline $72-75$ & 46.5 & 47.1 & 48.1 & 50.0 & 52.4 & 55.1 & 58.0 & 60.0 & 61.4 \\
\hline $75-78$ & 46.7 & 47.3 & 48.3 & 50.2 & 52.6 & 55.4 & 58.4 & 60.4 & 61.8 \\
\hline $78-81$ & 46.9 & 47.5 & 48.6 & 50.4 & 52.8 & 55.7 & 58.7 & 60.8 & 62.2 \\
\hline $81-84$ & 47.1 & 47.7 & 48.8 & 50.6 & 53.1 & 55.9 & 59.0 & 61.1 & 62.6 \\
\hline
\end{tabular}


and 3 , the selected waist circumference percentiles including 3rd, 10th 25th, 50th, 75th, 90th, and 97th percentiles are shown for each age and gender. The LMS parameters for waist circumference are shown in Table 4. The mean and 1, 2, 3 standard deviations added and subtracted WC for each age group and gender are shown in Tables 5 and 6.

In comparison to 10th, 50th, and 90th percentiles between genders, boys' WC were longer than girls' after the infancy period (Fig. 1).

We also compared the frequency of WC higher than 90th percentile between each gender to reveal the fluctuations in abdominal obesity prevalence (Fig. 2). The 10th, 50th, and 90th percentiles of our study were compared with other studies, the methodologies of which are similar to ours (Figs. 3 and 4).

\section{Discussion}

This is the first cross-sectional study for age- and genderspecific references of 0 - to 6-year-old Turkish children. In addition to finding a slightly low WC in girls compared with boys, in comparison with other studies in similar age groups, the WC of boys and girls were lower. The ageand gender-specific prevalence of abdominal obesity was also calculated. Because of difficulty in sampling in infancy and preschool children and the high number of studies about obesity prevalence in school children and adolescence, we concentrated on infants and preschool children [22, 42].

Early-onset obesity ( $<6$ years) not only increases the risk of metabolic and cardiovascular disorders in adulthood but also indicates that the risk of adult obesity would be increased by at least $25-50 \%[14,25,31]$. Then, this study
Table 4 The power of a BoxCox transformation (L), the median (M), and the coefficient of variation (S) for waist circumference for both genders

\begin{tabular}{|c|c|c|c|c|c|c|}
\hline \multirow[t]{2}{*}{ Age } & \multicolumn{3}{|l|}{ Boys } & \multicolumn{3}{|l|}{ Girls } \\
\hline & $\mathrm{L}$ & M & S & $\mathrm{L}$ & M & $\mathrm{S}$ \\
\hline $0-28$ days & 3.030 & 31.185 & 0.067 & -0.192 & 31.449 & 0.081 \\
\hline 28 days -3 months & 1.360 & 37.206 & 0.070 & -0.147 & 36.813 & 0.075 \\
\hline $3-<6$ & 0.611 & 40.042 & 0.070 & -0.098 & 39.488 & 0.072 \\
\hline $6-<9$ & 0.201 & 41.691 & 0.070 & -0.078 & 41.134 & 0.069 \\
\hline $9-<12$ & -0.061 & 42.835 & 0.068 & -0.099 & 42.320 & 0.068 \\
\hline $12-<15$ & -0.258 & 43.731 & 0.067 & -0.143 & 43.266 & 0.067 \\
\hline $15-<18$ & -0.424 & 44.503 & 0.066 & -0.207 & 44.079 & 0.066 \\
\hline $18-<21$ & -0.578 & 45.210 & 0.066 & -0.288 & 44.814 & 0.066 \\
\hline $21-<24$ & -0.729 & 45.879 & 0.065 & -0.383 & 45.498 & 0.066 \\
\hline $24-<27$ & -0.881 & 46.517 & 0.065 & -0.489 & 46.141 & 0.066 \\
\hline $27-<30$ & -1.034 & 47.123 & 0.065 & -0.600 & 46.742 & 0.066 \\
\hline $30-<33$ & -1.188 & 47.695 & 0.064 & -0.715 & 47.306 & 0.066 \\
\hline $33-<36$ & -1.342 & 48.236 & 0.064 & -0.833 & 47.833 & 0.066 \\
\hline $36-<39$ & -1.493 & 48.747 & 0.064 & -0.949 & 48.324 & 0.067 \\
\hline $39-<42$ & -1.642 & 49.229 & 0.065 & -1.065 & 48.783 & 0.067 \\
\hline $42-45$ & -1.787 & 49.684 & 0.065 & -1.178 & 49.212 & 0.068 \\
\hline $45-<48$ & -1.927 & 50.114 & 0.065 & -1.289 & 49.614 & 0.068 \\
\hline $48-<51$ & -2.062 & 50.519 & 0.065 & -1.396 & 49.991 & 0.069 \\
\hline $51-<54$ & -2.192 & 50.903 & 0.066 & -1.500 & 50.346 & 0.069 \\
\hline $54-<57$ & -2.318 & 51.266 & 0.066 & -1.600 & 50.680 & 0.070 \\
\hline $57-<60$ & -2.438 & 51.611 & 0.066 & -1.697 & 50.996 & 0.070 \\
\hline $60-<63$ & -2.553 & 51.938 & 0.067 & -1.790 & 51.295 & 0.070 \\
\hline $63-<66$ & -2.664 & 52.250 & 0.067 & -1.880 & 51.580 & 0.071 \\
\hline $66-<69$ & -2.770 & 52.548 & 0.067 & -1.967 & 51.852 & 0.071 \\
\hline $69-<72$ & -2.871 & 52.833 & 0.067 & -2.051 & 52.112 & 0.072 \\
\hline $72-75$ & -2.968 & 53.107 & 0.068 & -2.131 & 52.362 & 0.072 \\
\hline $75-78$ & -3.062 & 53.371 & 0.068 & -2.209 & 52.602 & 0.072 \\
\hline $78-81$ & -3.152 & 53.625 & 0.068 & -2.284 & 52.834 & 0.073 \\
\hline $81-84$ & -3.239 & 53.870 & 0.069 & -2.356 & 53.057 & 0.073 \\
\hline
\end{tabular}


Table 5 The mean and 1, 2, and 3 standard deviations added and subtracted WC for boys

\begin{tabular}{|c|c|c|c|c|c|c|c|}
\hline Age & $-3 \mathrm{SD}$ & $-2 \mathrm{SD}$ & $-1 \mathrm{SD}$ & mean & $+1 \mathrm{SD}$ & $+2 \mathrm{SD}$ & $+3 \mathrm{SD}$ \\
\hline $0-28$ days & 36.6 & 27.1 & 29.0 & 30.9 & 32.8 & 34.7 & 36.6 \\
\hline 28 days -3 months & 47.5 & 31.5 & 34.7 & 37.9 & 41.1 & 44.3 & 47.5 \\
\hline $3-<6 \mathrm{~m}$ & 49.8 & 34.8 & 37.8 & 40.8 & 43.8 & 46.8 & 49.8 \\
\hline $6-<9 \mathrm{~m}$ & 51.4 & 35.4 & 38.6 & 41.8 & 45.0 & 48.2 & 51.4 \\
\hline $9-<12 \mathrm{~m}$ & 53.7 & 36.7 & 40.1 & 43.5 & 46.9 & 50.3 & 53.7 \\
\hline $12-<15 \mathrm{~m}$ & 52.6 & 38.1 & 41.0 & 43.9 & 46.8 & 49.7 & 52.6 \\
\hline $15-<18 \mathrm{~m}$ & 52.5 & 39.0 & 41.7 & 44.4 & 47.1 & 49.8 & 52.5 \\
\hline $18-<21 \mathrm{~m}$ & 53.0 & 38.5 & 41.4 & 44.3 & 47.2 & 50.1 & 53.0 \\
\hline $21-<24 \mathrm{~m}$ & 52.4 & 39.4 & 42.0 & 44.6 & 47.2 & 49.8 & 52.4 \\
\hline $24-<27 \mathrm{~m}$ & 55.4 & 40.9 & 43.8 & 46.7 & 49.6 & 52.5 & 55.4 \\
\hline $27-<30 \mathrm{~m}$ & 55.5 & 42.5 & 45.1 & 47.7 & 50.3 & 52.9 & 55.5 \\
\hline $30-<33 \mathrm{~m}$ & 55.9 & 41.9 & 44.7 & 47.5 & 50.3 & 53.1 & 55.9 \\
\hline $33-<36 \mathrm{~m}$ & 56.6 & 42.1 & 45.0 & 47.9 & 50.8 & 53.7 & 56.6 \\
\hline $36-<39 \mathrm{~m}$ & 56.9 & 43.9 & 46.5 & 49.1 & 51.7 & 54.3 & 56.9 \\
\hline $39-<42 \mathrm{~m}$ & 59.9 & 43.4 & 46.7 & 50.0 & 53.3 & 56.6 & 59.9 \\
\hline $42-45 \mathrm{~m}$ & 58.0 & 44.0 & 46.8 & 49.6 & 52.4 & 55.2 & 58.0 \\
\hline $45-<48 \mathrm{~m}$ & 58.0 & 45.0 & 47.6 & 50.2 & 52.8 & 55.4 & 58.0 \\
\hline $48-<51 \mathrm{~m}$ & 61.1 & 44.6 & 47.9 & 51.2 & 54.5 & 57.8 & 61.1 \\
\hline $51-<54 \mathrm{~m}$ & 62.1 & 44.1 & 47.7 & 51.3 & 54.9 & 58.5 & 62.1 \\
\hline $54-<57 \mathrm{~m}$ & 64.1 & 44.6 & 48.5 & 52.4 & 56.3 & 60.2 & 64.1 \\
\hline $57-<60 \mathrm{~m}$ & 61.6 & 46.6 & 49.6 & 52.6 & 55.6 & 58.6 & 61.6 \\
\hline $60-<63 \mathrm{~m}$ & 64.4 & 45.4 & 49.2 & 53.0 & 56.8 & 60.6 & 64.4 \\
\hline $63-<66 \mathrm{~m}$ & 64.1 & 45.1 & 48.9 & 52.7 & 56.5 & 60.3 & 64.1 \\
\hline $66-<69 \mathrm{~m}$ & 70.8 & 43.3 & 48.8 & 54.3 & 59.8 & 65.3 & 70.8 \\
\hline $69-<72 \mathrm{~m}$ & 64.8 & 44.3 & 48.4 & 52.5 & 56.6 & 60.7 & 64.8 \\
\hline $72-<75 \mathrm{~m}$ & 65.4 & 46.4 & 50.2 & 54.0 & 57.8 & 61.6 & 65.4 \\
\hline $75-<78 \mathrm{~m}$ & 63.6 & 45.1 & 48.8 & 52.5 & 56.2 & 59.9 & 63.6 \\
\hline $78-<81 \mathrm{~m}$ & 68.7 & 45.7 & 50.3 & 54.9 & 59.5 & 64.1 & 68.7 \\
\hline $81-<84 \mathrm{~m}$ & 69.6 & 45.6 & 50.4 & 55.2 & 60.0 & 64.8 & 69.6 \\
\hline
\end{tabular}

would at least provide the opportunity of determining the validity of the preceding statement by comparing with future similar cross-sectional studies in our population.

There is a moderate correlation between obesity in early childhood and in adulthood [16]. In a report by Nader et al., the authors stated that preschool children whose BMIs were higher than 50p would have six-times-higher risk of overweight in later childhood [28]. In addition to these findings, obesity at the age of 5 was proposed as the predictor of metabolic status at 9 years old [42]. Then, early interventions to treat obesity would not only have a short time but would also have a long period of consecutions [2]. WC references which were determined in this study would be useful to determine metabolic risks in early childhood since a similar study was not done in our population.

It is known that there is a decrease in BMI from infancy to 6 years old, the so-called adiposity rebounds, but because of individual variations during this period any two children who have the same BMI may be at different levels of adiposity. Since the onset of adiposity rebound varies individually in this period, children whose adiposity onset is early may have similar BMIs with the relatively late-onset one [33]. Thus, in preschool children ( $<6$ years old), we may conclude that the use of BMI to predict adiposity is not reliable. Additionally, in this period, non-uniform segmental growth leads the need to use WC but not BMI since BMI reflects total body fat content but not body fat distribution [3, 4, 32]. BMI may define large central fat deposits as normal, while it has poor sensitivity to define central obesity [32]. Therefore, WC prevents misclassification for central fat deposit and minimizes individual variation [39]. Since WC in children has a good correlation with insulin resistance, it is considered as a useful tool to predict the risk of developing metabolic and cardiovascular complications [23]. The correlation between WC and central adiposity is also confirmed by dual-energy X-ray absorptiometry [39]. The rationale of this study depends on this hypothesis that segmental fat distribution is best reflected by WC compared with BMI. 
Table 6 The mean and 1,2, and 3 standard deviations added and subtracted WC for girls

\begin{tabular}{|c|c|c|c|c|c|c|c|}
\hline Age & $-3 \mathrm{SD}$ & $-2 \mathrm{SD}$ & $-1 \mathrm{SD}$ & Mean & $+1 \mathrm{SD}$ & $+2 \mathrm{SD}$ & $+3 \mathrm{SD}$ \\
\hline $0-28$ days & 23.5 & 26.1 & 28.7 & 31.3 & 33.9 & 36.5 & 44.3 \\
\hline 28 days -3 months & 28.3 & 31.4 & 34.5 & 37.6 & 40.7 & 43.8 & 53.1 \\
\hline $3-<6 \mathrm{~m}$ & 31.5 & 34.4 & 37.3 & 40.2 & 43.1 & 46.0 & 54.7 \\
\hline $6-<9 \mathrm{~m}$ & 31.9 & 35.0 & 38.1 & 41.2 & 44.3 & 47.4 & 56.7 \\
\hline $9-<12 \mathrm{~m}$ & 33.4 & 36.5 & 39.6 & 42.7 & 45.8 & 48.9 & 58.2 \\
\hline $12-<15 \mathrm{~m}$ & 34.9 & 37.8 & 40.7 & 43.6 & 46.5 & 49.4 & 58.1 \\
\hline $15-<18 \mathrm{~m}$ & 35.8 & 38.6 & 41.4 & 44.2 & 47.0 & 49.8 & 58.2 \\
\hline $18-<21 \mathrm{~m}$ & 36.5 & 39.0 & 41.5 & 44.0 & 46.5 & 49.0 & 56.5 \\
\hline $21-<24 \mathrm{~m}$ & 36.8 & 39.5 & 42.2 & 44.9 & 47.6 & 50.3 & 58.4 \\
\hline $24-<27 \mathrm{~m}$ & 37.4 & 40.4 & 43.4 & 46.4 & 49.4 & 52.4 & 61.4 \\
\hline $27-<30 \mathrm{~m}$ & 37.7 & 40.7 & 43.7 & 46.7 & 49.7 & 52.7 & 61.7 \\
\hline $30-<33 \mathrm{~m}$ & 39.1 & 41.6 & 44.1 & 46.6 & 49.1 & 51.6 & 59.1 \\
\hline $33-<36 \mathrm{~m}$ & 37.7 & 41.3 & 44.9 & 48.5 & 52.1 & 55.7 & 66.5 \\
\hline $36-<39 \mathrm{~m}$ & 40.7 & 43.5 & 46.3 & 49.1 & 51.9 & 54.7 & 63.1 \\
\hline $39-<42 \mathrm{~m}$ & 39.0 & 42.4 & 45.8 & 49.2 & 52.6 & 56.0 & 66.2 \\
\hline $42-45 \mathrm{~m}$ & 38.5 & 41.9 & 45.3 & 48.7 & 52.1 & 55.5 & 65.7 \\
\hline $45-<48 \mathrm{~m}$ & 38.8 & 42.7 & 46.6 & 50.5 & 54.4 & 58.3 & 70.0 \\
\hline $48-<51 \mathrm{~m}$ & 41.2 & 44.3 & 47.4 & 50.5 & 53.6 & 56.7 & 66.0 \\
\hline $51-<54 \mathrm{~m}$ & 39.9 & 43.7 & 47.5 & 51.3 & 55.1 & 58.9 & 70.3 \\
\hline $54-<57 \mathrm{~m}$ & 40.5 & 44.2 & 47.9 & 51.6 & 55.3 & 59.0 & 70.1 \\
\hline $57-<60 \mathrm{~m}$ & 39.0 & 43.4 & 47.8 & 52.2 & 56.6 & 61.0 & 74.2 \\
\hline $60-<63 \mathrm{~m}$ & 40.3 & 44.0 & 47.7 & 51.4 & 55.1 & 58.8 & 69.9 \\
\hline $63-<66 \mathrm{~m}$ & 42.0 & 45.6 & 49.2 & 52.8 & 56.4 & 60.0 & 70.8 \\
\hline $66-<69 \mathrm{~m}$ & 38.8 & 43.2 & 47.6 & 52.0 & 56.4 & 60.8 & 74.0 \\
\hline $69-<72 \mathrm{~m}$ & 39.5 & 43.7 & 47.9 & 52.1 & 56.3 & 60.5 & 73.1 \\
\hline $72-<75 \mathrm{~m}$ & 38.5 & 43.1 & 47.7 & 52.3 & 56.9 & 61.5 & 75.3 \\
\hline $75-<78 \mathrm{~m}$ & 42.3 & 45.7 & 49.1 & 52.5 & 55.9 & 59.3 & 69.5 \\
\hline $78-<81 \mathrm{~m}$ & 41.1 & 45.5 & 49.9 & 54.3 & 58.7 & 63.1 & 76.3 \\
\hline $81-<84 \mathrm{~m}$ & 39.7 & 44.2 & 48.7 & 53.2 & 57.7 & 62.2 & 75.7 \\
\hline
\end{tabular}

The primary contribution of this study is to provide the first WC references in Turkish preschool children to our knowledge. Our findings indicate that the increase in WC through early childhood is faster than 1.5 to 6 years. According to our findings, predominance in central adiposity for boys compared with girls may be an indicator of sexual dimorphism in early childhood in accordance with previous studies [15, 38].

Although there are different cutoffs to define central obesity, we used $\mathrm{WC}>90$ th percentile since it was proposed as the prerequisite in the definition of metabolic syndrome. In addition to smoothed references (3rd, 10th 25 th, 50th, 75 th, 90th, and 97th percentiles), we presented all descriptive characteristics of our data (mean, median, standard deviations) to let other researchers make comments on our results. The cited methods to define cutoff for WC can be stated as: $z$ score $\geq 1.3$ by Fredrick, $z$ score $\geq 1.5$ by Taylor, at $>75$ th by Moreno, and age- and sex-specific 90th by Katzmarzyk [12, 18, 26, 39].
Increased $\mathrm{WC}>90$ th percentile is proposed by NCEPATP III and IDF, but cutoff for WC to define metabolic syndrome is lacking before 10 years old [9, 40, 41]. However, in recent studies, to diagnose metabolic risk, it is suggested that modified IDF and NCEP criteria can be used in the pre-pubertal period (6-10 years) $[6,14,45]$. In these modified criteria, WC $>90$ th percentile was accepted as cutoff value to define metabolic risk at older than 10 years. Although cutoff for abdominal obesity is not determined under 6 years, $\mathrm{WC}>90$ th percentile may be speculated at this level of knowledge [6, 14]. According to this criterion, we found total abdominal obesity prevalence as $10.4 \%$ (boys $10.1 \%$, girls $10.7 \%$ ), where age-adjusted prevalence values were also given.

We also compared the frequency of WC higher than 90th percentile between each gender and found significant fluctuations until the age of 2 years. After 2 years, WC showed a small decline until 3 years and it was followed by a gradual increase until 6 years in both genders, where 
Fig. 1 The comparison of 10th, 50th, and 90th percentile between genders

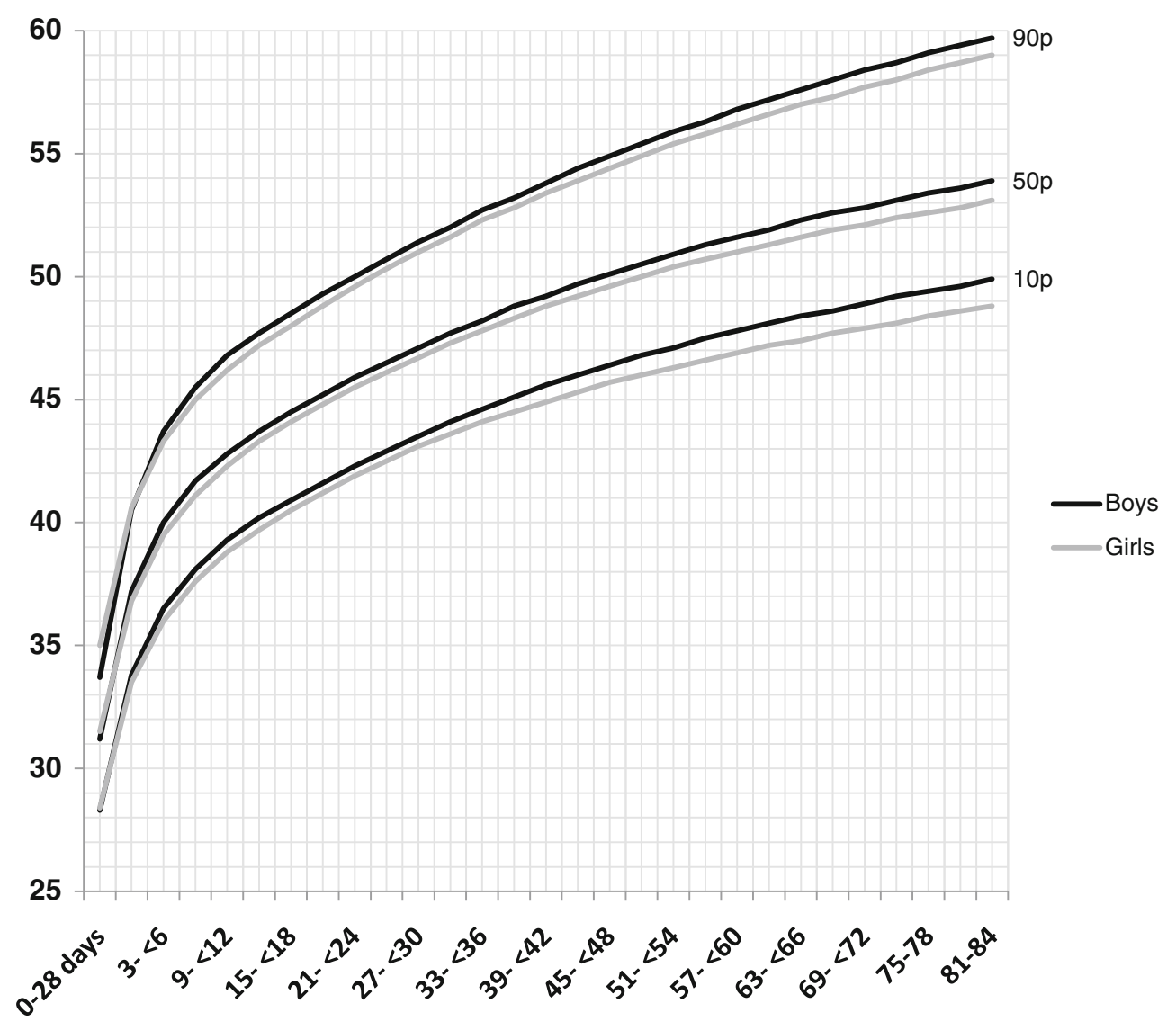

abdominal obesity was higher in girls during this period (Fig. 2). The observation that the increase in abdominal obesity was shifted towards the early years can be interpreted as early rebound. Although BMI and WC do not completely reflect the same metabolic parameters, early onset of abdominal obesity may require the onset of rebound obesity for BMI. Since WC reflects primarily the body fat distribution but not total body fat, inconsistent obesity rebounds in WC and BMI must be evaluated separately.
Fig. 2 The frequency of WC higher than 90th percentile between each gender

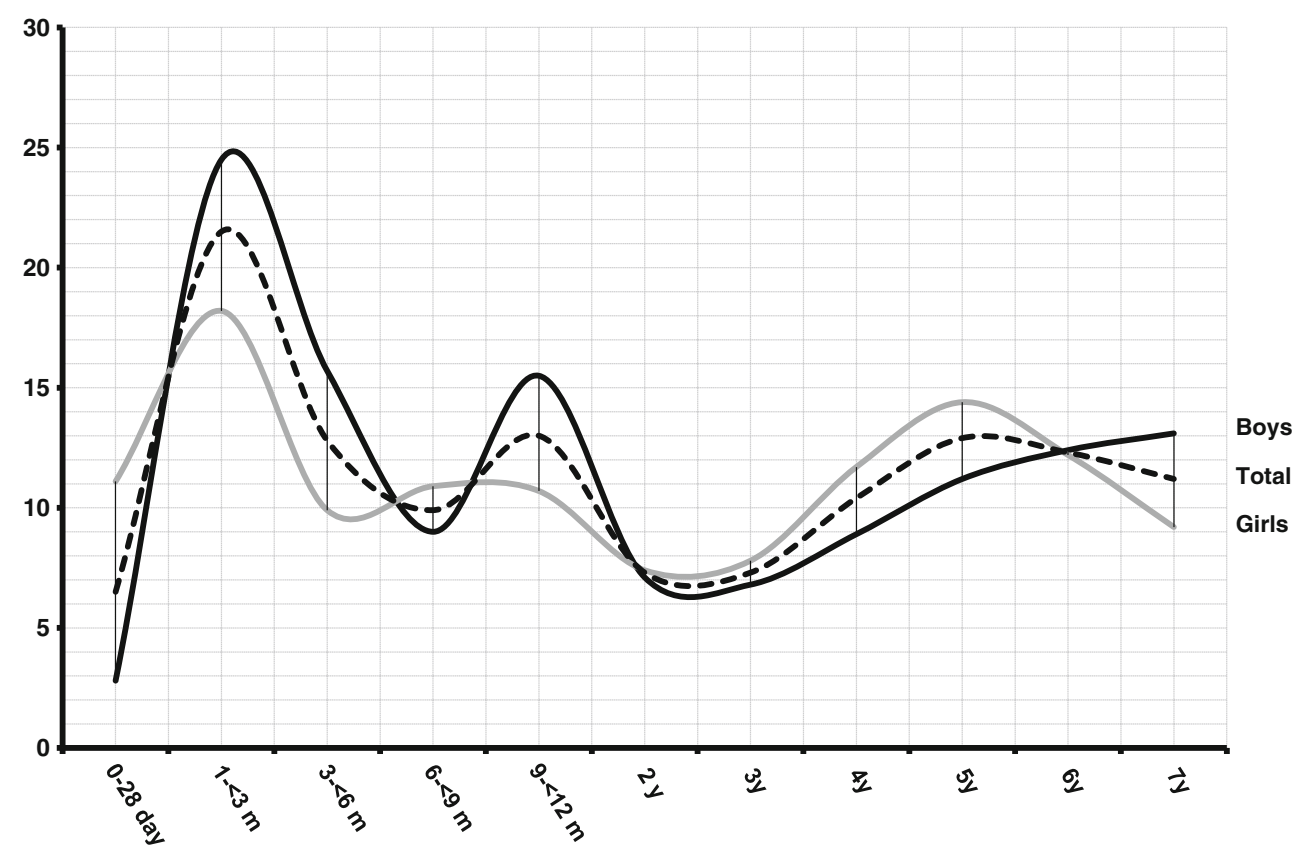


Fig. 3 The comparison of 10th, 50th, and 90th percentiles of our WC (Turkey) with the preschool children of German (Ger) and European American (Eu Am) for boys

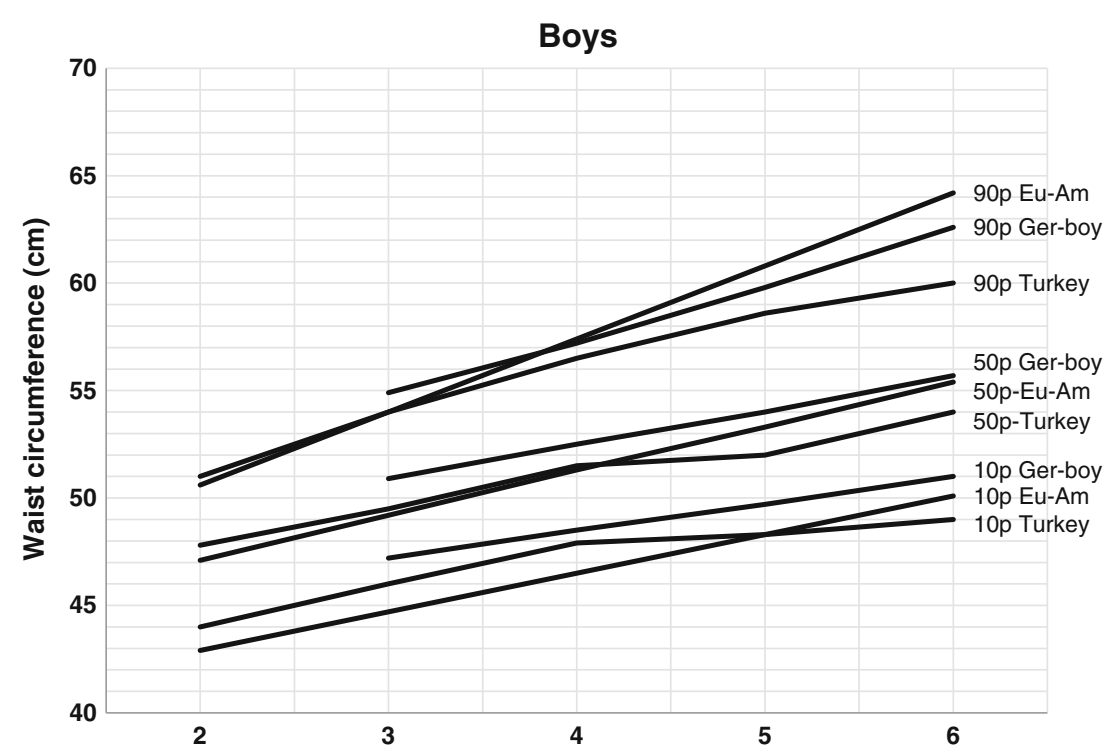

There are few studies about WC percentiles for children under 6 years old. In a study conducted in Sweden on children less than 5 year old, SDS values are calculated for WC, but not percentiles. This prevented us to make a comparison of percentiles [34]. In another study conducted in 316-year-old Indian children, there were calculated percentiles which can be compared with our references. We could not make a comparison with those since they were not Caucasian [21]. We selected two previous studies providing WC references with a similar method in the same age of Caucasians. One of them was calculated WC percentiles in 3-11-year-old German children. The other one was a study conducted in 2-18-year-old European American children in
USA $[11,37]$. In comparing our data with these two studies, we found that our WC references were significantly lower than those (Figs. 3 and 4). These differences may be explained by dissimilarities in ethnic, geographical, and nutritional behaviors as well as lifestyle. Even in the prepubertal period, these dissimilarities may be observed [11].

We consider that behaviors related to sedentary activities such as watching television and/or playing with electronic games are established in the preschool period. Our data can then be used to determine the risk of central obesity in early childhood. We can conclude that WC together with BMI is a useful clinical tool to detect preschool-age children who may be at a higher risk for cardiovascular diseases.
Fig. 4 The comparison of 10th, 50th, and 90th percentiles of our WC (Turkey) with the preschool children of German (Ger) and European American $(\mathrm{Eu} \mathrm{Am})$ for girls

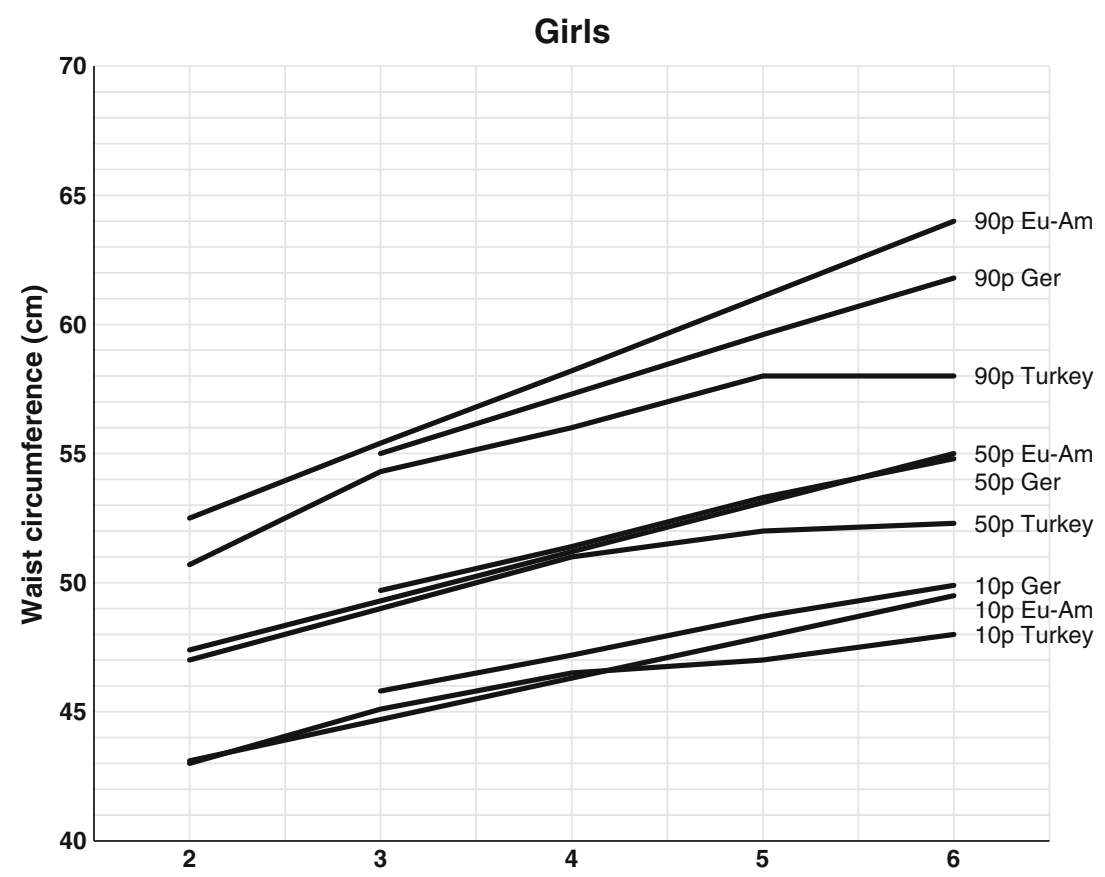


Open Access This article is distributed under the terms of the Creative Commons Attribution License which permits any use, distribution, and reproduction in any medium, provided the original author(s) and the source are credited.

\section{References}

1. Aeberli I, Gut-Knabenhans I, Kusche-Ammann RS, Molinari L, Zimmermann MB (2011) Waist circumference and waist-to-height ratio percentiles in a nationally representative sample of 6-13 year old children in Switzerland. Swiss Med Wkly. doi:10.4414/ smw.2011.13227

2. Bluford DA, Sherry B, Scanlon KS (2007) Interventions to prevent or treat obesity in preschool children: a review of evaluated programs. Obesity 15:1356-1372

3. Bogin B (1999) Basic principles of human growth. In: Bogin B (ed) Patterns of human growth, 2nd edn. Cambridge University Press, Cambridge

4. Cameron N (2008) The biology of growth. Nestle Nutr Work Ser Pediatr Program 61:1-19

5. Centers for Disease Control and Prevention (2007) Obesity among adults in the Unites States - no statistically significant change since 2003-2004. http://www.cdc.gov/nchs/pressrom/07newsreleases/ obesity.htm. Accessed 6 April 2010

6. Chi CH, Wang Y, Wilson DM, Robinson TN (2006) Definition of metabolic syndrome in preadolescent girls. J Pediatr 148:788-792

7. Cole TJ (1988) Fitting smoothed centile curves to reference data. JR Stat Soc 151:385-418

8. Cole TJ, Green PJ (1992) Smoothing reference centile curves: The LMS method and penalized likelihood. Stat Med 11:1305-1319

9. de Ferranti SD, Gauvreau K, Ludwig DS, Neufeld EJ, Newburger JW, Rifai N (2004) Prevalence of the metabolic syndrome in American adolescents: Findings from the Third National Health and Nutrition Examination Survey. Circulation 110: 2494-2497

10. de Onis M, Garza C, Victora CG, Onyango AW, Frongillo EA, Martines J (2004) The WHO multicentre growth reference study: Planning, study design, and methodology. Food Nutr Bull 25:S15S26

11. Fernandez JR, Redden DT, Pietrobelli A, Allison DB (2004) Waist circumference percentiles in nationally representative samples of African-American, European-American, and Mexican-American children and adolescents. J Pediatr 145:439-444

12. Fredriks AM, van Buuren S, Fekkes M, Verloove-Vanhorick SP, Wit JM (2005) Are age references for waist circumference, hip circumference and waist-hip ratio in Dutch children useful in clinical practice? Eur J Pediatr 164:216-222

13. Garza C, de Onis M (2004) Rationale for developing a new international growth reference. Food Nutr Bull 25:S5-S14

14. Golley RK, Magarey AM, Steinbeck KS, Baur LA, Daniels LA (2006) Comparison of metabolic syndrome prevalence using six different definitions in overweight pre-pubertal children enrolled in a weight management study. Int J Obes 30:853-860

15. Goran MI, Kaskoun M, Johnson R, Martinez C, Kelly B, Hood V (1995) Energy expenditure and body fat distribution in Mohawk children. Pediatrics 95:89-95

16. Guo SS, Huang C, Maynard LM, Demerath E, Towne B, Chumlea WC, Siervogel RM (2000) Body mass index during childhood, adolescence and young adulthood in relation to adult overweight and adiposity: the Fels Longitudinal Study. Int J Obes Relat Metab Disord 24:1628-1635

17. Hatipoglu N, Ozturk A, Mazicioglu MM, Kurtoglu S, Seyhan S, Lokoglu F (2008) Waist circumference percentiles for 7- to 17- year-old Turkish children and adolescents. Eur J Pediatr 167:383389

18. Katzmarzyk PT (2004) Waist circumference percentiles for Canadian youth 11-18y of age. Eur J Clin Nutr 58:1011-1015

19. Kindblom JM, Lorentzon M, Hellqvist A, Lonn L, Brandberg J, Nilsson S, Norjavaara E, Ohlsson C (2009) BMI changes during childhood and adolescence as predictors of amount of adult subcutaneous and visceral adipose tissue in men - the GOOD Study. Diabetes 58:867-874

20. Kromeyer-Hauschild K, Dortschy R, Stolzenberg H, Neuhauser H, Rosario AS (2011) Nationally representative waist circumference percentiles in German adolescents aged $11.0-18.0$ years. Int $\mathrm{J}$ Pediatr Obes 6:e129-e137

21. Kuriyan R, Thomas T, Lokesh DP, Sheth NR, Mahendra A, Joy R, Sumithra S, Bhat S, Kurpad AV (2011) Waist circumference and waist for height percentiles in urban South Indian children aged 3 16 years. Indian Pediatr 48:765-771

22. Lobstein T, Frelut ML (2003) Prevalence of overweight among children in Europe. Obes Rev 4:195-200

23. Maffeis C, Pietrobelli A, Grezzani A, Provera S, Tató L (2001) Waist circumference and cardiovascular risk factors in prepubertal children. Obes Res 9:179-187

24. McCarthy HD, Jarrett KV, Crawley HF (2001) The development of waist circumference percentiles in British children aged 5.0 to 16.9 y. Eur J Clin Nutr 55:902-907

25. Mei Z, Grummer-Strawn LM, Scanlon KS (2003) Does overweight in infancy persist through the preschool years? An analysis of CDC Pediatric Nutrition Surveillance System data. Soz Praventivmed 48:161-167

26. Moreno LA, Pineda I, Rodriguez G, Fleta J, Sarria A, Bueno M (2002) Waist circumference for the screening of the metabolic syndrome in children. Acta Paediatr 91:1307-1312

27. Mushtaq MU, Gull S, Abdullah HM, Shahid U, Shad MA, Akram J (2011) Waist circumference, waist-hip ratio and waist-height ratio percentiles and central obesity among Pakistani children aged five to twelve years. BMC Pediatr 21:105

28. Nader PR, O'Brien M, Houts R, Bradley R, Belsky J, Crosnoe R, Friedman S, Mei Z, Susman EJ (2006) National institute of child health and human development early child care research network. Identifying risk for obesity in early childhood. Pediatrics 118: e594-e601

29. Ogden CL, Carroll MD, Kit BK, Flegal KM (2012) Prevalence of obesity and trends in body mass index among US children and adolescents, 1999-2010. JAMA 307:483-490

30. Olza J, Gil-Campos M, Leis R, Bueno G, Aguilera CM, Valle M, Cañete R, Tojo R, Moreno LA, Gil A (2011) Presence of the metabolic syndrome in obese children at prepubertal age. Ann Nutr Metab 58:343-350

31. Quattrin T, Liu E, Shaw N, Shine B, Chiang E (2005) Obese children who are referred to the pediatric endocrinologist: characteristics and outcome. Pediatrics 115:348-351

32. Reilly JJ, Dorosty AR, Emmett PM (2000) Avon longitudinal study of pregnancy and childhood study team. Identification of the obese child: adequacy of the body mass index for clinical practice and epidemiology. Int J Obes Relat Metab Disord 24:1623-1627

33. Rolland-Cachera MF, Deheeger M, Bellisle F, Sempe M, GuilloudBataille M, Patois E (1984) Adiposity rebound in children: A simple indicator for predicting obesity. Am J Clin Nutr 39:129135

34. Roswall J, Bergman S, Almqvist-Tangen G, Alm B, Niklasson A, Nierop AF, Dahlgren J (2009) Population-based waist circumference and waist-to-height ratio reference values in preschool children. Acta Paediatr 98:1632-1636

35. Sardinha LB, Santos R, Vale S, Silva EMJ, Raimundo AM, Moreira H, Baptista F, Mota J (2012) Waist circumference percentiles for 
Portuguese children and adolescents aged 10 to 18 years. Eur J Pediatr 171:499-505

36. Savva S (2000) Waist circumference and waist-to-height ratio are better predictors of cardiovascular disease risk factors in children than body mass index. Int J Obes Relat Metab Disord 24:14531458

37. Schwandt P, Kelishadi R, Haas GM (2008) First reference curves of waist circumference for German children in comparison to international values: The PEP Family Heart Study. World J Pediatr 4:259-266

38. Taylor RW, Gold E, Manning P, Goulding A (1997) Gender differences in body fat content are present well before puberty. Int $\mathrm{J}$ Obes Relat Metab Disord 21:1082-1084

39. Taylor RW, Jones IE, Williams SM, Goulding A (2000) Evaluation of waist circumference, waist-to-hip ratio, and the conicity index as screening tools for high trunk fat mass, as measured by dualenergy X-ray absorptiometry, in children aged 3-19 y. Am J Clin Nutr 72:490-495
40. Third report of the National Cholesterol Education Program (NCEP) Expert Panel on Detection, Evaluation, and Treatment of High Blood Cholesterol in Adults (Adults Treatment Panel III) final report (2002) Circulation 106:3143

41. The IDF consensus worldwide definition of the metabolic syndrome (2006). Available at: http://www.idf.org/webdata/docs/ MetS_def_update2006.pdf

42. Wang Y, Lobstein T (2006) Worldwide trends in childhood overweight and obesity. Int J Pediatr Obes 1:11-25

43. World Health Organisation (1995) Physical status: The use and interpretation of anthropometry: A report of a WHO Expert Committee. WHO, Geneva

44. World Health Organization (2005) Preventing chronic diseases: A vital investment. World global report. World Health Organization, Geneva

45. Zimmet P, Alberti KG, Kaufman F, Tajima N, Silink M, Arslanian S, Wong G, Bennett P, Shaw J, Caprio S (2007) IDF Consensus Group. The metabolic syndrome in children and adolescents - an IDF consensus report. Pediatr Diabetes 8:299-306 